\title{
Article
}

\section{Defect-Controlled Electronic Structure and Phase Stability in Thermoelectric Skutterudite CoSb}

Guodong Li, Umut Aydemir, Max Wood, William A. Goddard

III, Pengcheng Zhai, Qingjie Zhang, and G. Jeffrey Snyder

Chem. Mater., Just Accepted Manuscript • DOI: 10.1021/acs.chemmater.7b00559 • Publication Date (Web): 17 Apr 2017

Downloaded from http://pubs.acs.org on April 18, 2017

\section{Just Accepted}

"Just Accepted" manuscripts have been peer-reviewed and accepted for publication. They are posted online prior to technical editing, formatting for publication and author proofing. The American Chemical Society provides "Just Accepted" as a free service to the research community to expedite the dissemination of scientific material as soon as possible after acceptance. "Just Accepted" manuscripts appear in full in PDF format accompanied by an HTML abstract. "Just Accepted" manuscripts have been fully peer reviewed, but should not be considered the official version of record. They are accessible to all readers and citable by the Digital Object Identifier (DOI®). "Just Accepted" is an optional service offered to authors. Therefore, the "Just Accepted" Web site may not include all articles that will be published in the journal. After a manuscript is technically edited and formatted, it will be removed from the "Just Accepted" Web site and published as an ASAP article. Note that technical editing may introduce minor changes to the manuscript text and/or graphics which could affect content, and all legal disclaimers and ethical guidelines that apply to the journal pertain. ACS cannot be held responsible for errors or consequences arising from the use of information contained in these "Just Accepted" manuscripts. 


\title{
Defect-Controlled Electronic Structure and Phase Stability in Thermoelectric Skutterudite $\mathrm{CoSb}_{3}$
}

\author{
Guodong Li ${ }^{\dagger, \ddagger}$, Umut Aydemir ${ }^{\ddagger}$, Max Wood ${ }^{\ddagger}$, William A. Goddard III ${ }^{\perp}$, Pengcheng Zhai ${ }^{\dagger}$, \\ Qingjie Zhang ${ }^{*}$, , and G. Jeffrey Snyder ${ }^{*}, \ddagger$ \\ ${ }^{\dagger}$ State Key Laboratory of Advanced Technology for Materials Synthesis and Processing, Wuhan University \\ of Technology, Wuhan 430070, China. \\ ${ }^{\ddagger}$ Department of Materials Science and Engineering, Northwestern University, Evanston, Illinois 60208, \\ USA. \\ ${ }^{\perp}$ Materials and Process Simulation Center, California Institute of Technology, Pasadena, California 91125, \\ USA. \\ *Corresponding authors: jeff.snyder@northwestern.edu; zhangqj@whut.edu.cn
}

\begin{abstract}
Controlling extrinsic defects to tune the carrier concentration of electrons or holes is a crucial point concerning the engineering application of thermoelectric semiconductors. To understand the defect-controlled electronic structure in thermoelectric materials, we apply density functional theory (DFT) to investigate the defect chemistry of dopants $M(M=\mathrm{O}, \mathrm{S}, \mathrm{Se}, \mathrm{Te})$ in $\mathrm{CoSb}_{3}$. DFT predicts that the breakage of $\mathrm{Sb}_{4}$-rings induced by these dopants produces the unexpected (n- or p-type) conductivity behavior in $\mathrm{CoSb}_{3}$. For example, energetically dominant $\mathrm{O}$ interstitials $\left(\mathrm{O}_{\mathrm{i}}\right)$ chemically break $\mathrm{Sb}_{4}$-rings and form $\mathrm{O}-4 \mathrm{Sb}$ five-membered rings, leading to the charge neutral behavior of $\mathrm{O}_{\mathrm{i}}$. While $\mathrm{S}$ interstitials $\left(\mathrm{S}_{\mathrm{i}}\right)$ collapse Te-3Sb four-membered rings within Te doped $\mathrm{CoSb}_{3}$ leading to a p-type conduction behavior, Se substitution on $\mathrm{Sb}\left(\mathrm{Se}_{\mathrm{Sb}}\right)$ breaks the Se-Te-2Sb four-membered ring resulting in a charge neutral behavior of the complex defect $\mathrm{Se}_{\mathrm{Sb}}+\mathrm{Te}_{\mathrm{Sb}}$. Furthermore, the solubility limits of $M$ dopants $(M=\mathrm{S}, \mathrm{Se}, \mathrm{Te})$ are also calculated to provide essential information on single-phase material design. This study provides a new insight to understand the complicated chemical structure in doped $\mathrm{CoSb}_{3}$, which is beneficial for devising effective doping strategies to develop high-performance bulk thermoelectric materials.
\end{abstract}

\section{INTRODUCTION}

Thermoelectric (TE) energy conversion techniques have attracted substantial attention because they can directly convert heat into electricity. Having no moving parts, thermoelectrics 
have lots of promising applications such as radioisotope TE power generation and recovery of automobile exhaust heat. ${ }^{1}$ The TE conversion efficiency is defined by $Z T=\left(\alpha^{2} \sigma\right) T / \kappa$, where $\alpha$ is the Seebeck coefficient, $\sigma$ is the electrical conductivity, $T$ is the absolute temperature, and $\kappa$ is the thermal conductivity. The challenge for rationally designing high performance TE materials is to enhance the power factor $\alpha^{2} \sigma$ while reducing the $\kappa .^{2}$

The guest (filler) and host atom interactions have significant effects on both electrical and thermal transport properties of materials with cage structures. ${ }^{3,4}$ Traditionally, the electropositive guest atoms in a crystal structure rattle inside the voids acting as an additional phonon scattering center, which may remarkably reduce the thermal conductivity to glassy limit. ${ }^{3}$ The covalently bonded framework on the other hand provides a pathway for efficient charge transport similarly found in a good semiconductor crystal. Among the many types of "phonon-glass-electron-crystal" TE materials, ${ }^{5} \mathrm{CoSb}_{3}$ based skutterudite has garnered high status and worldwide attention because both $n$ - and p- type doped $\mathrm{CoSb}_{3}$ exhibit excellent TE and mechanical properties. ${ }^{6-9}$ Understanding and controlling extrinsic point defects are essential for preparing and optimizing the carrier concentration of $\mathrm{CoSb}_{3}$ with excellent TE properties. Two defect-chemical approaches are used to optimize the TE performance of $\mathrm{CoSb}_{3}$. The first one is introducing a filler atom (La, $\mathrm{Ce}, \mathrm{Yb}, \mathrm{Ba}, \mathrm{In}, \mathrm{Ga}$, etc.) into the lattice cages of the $\mathrm{CoSb}_{3}$ structure to remarkably reduce the $\kappa$ thermal conductivity. ${ }^{10-16}$ For example, Shi et al. proposed a simple electronegativity rule to determine whether a skutterudite phase with guest atoms can stably form. ${ }^{16}$ The filling fraction limit (FFLs) of guest atoms was predicted in $\mathrm{CoSb}_{3}$ by considering not only the interaction between the guest and host atoms but also the formation of secondary phases. ${ }^{16}$ Later, electropositive $\mathrm{Ga}$ and $\mathrm{In}$ were reported to fill the voids in $\mathrm{CoSb}_{3}$ through self-compensation interactions between $\mathrm{Ga}$ (or In) and $\mathrm{Sb}^{15}$ Very recently, $\mathrm{CoSb}_{3}$ filled with electronegative atoms ( $\mathrm{S}$ and $\mathrm{Se}$ ) were successfully prepared with a strong covalent guest-host interactions between $\mathrm{S}$ (or Se) and Sb, which leads to very low lattice thermal conductivity. ${ }^{17}$ The second approach is substituting $\mathrm{Co}$ or $\mathrm{Sb}$ atoms with metals or semimetals to tune the electronic properties, ${ }^{17-23}$ and lots of experimental studies show VIA-group element $(\mathrm{O}, \mathrm{S}, \mathrm{Se}, \mathrm{Te})$ dopants can significantly influence the TE properties of $\mathrm{CoSb}_{3}{ }^{17,18,24-27}$

For Te doped $\mathrm{CoSb}_{3}$, Te substituting $\mathrm{Sb}\left(\mathrm{Te} \mathrm{Sb}_{\mathrm{b}}\right)$ would be the dominant point defect. For example, Li et al. reported $\mathrm{Co}_{4} \mathrm{Sb}_{12-x} \mathrm{Te}_{x}$ was successfully synthesized by using a melting method combined with spark plasma sintering (SPS), and the nominal solubility limit of Te substituting $\mathrm{Sb}$ was estimated to be $x=0.55$. The optimized $\mathrm{Co}_{4} \mathrm{Sb}_{11.5} \mathrm{Te}_{0.5}$ had a $z T$ value of 0.72 at $850 \mathrm{~K}^{24}$ However, $\mathrm{Co}_{4} \mathrm{Sb}_{11.5} \mathrm{Te}_{0.5}$ synthesized through a high pressure method followed by SPS had a 
maximum $z T$ value of 1.15 at $883 \mathrm{~K} .{ }^{18}$ Liu et al. fabricated $\mathrm{Co}_{4} \mathrm{Sb}_{12-\mathrm{x}} \mathrm{Te}_{\mathrm{x}}$ skutterudite polycrystals through mechanical alloying combined with SPS and found that the nominal solution limit of Te substituting $\mathrm{Sb}$ was $x=0.6$. The maximum $z T$ value of 0.93 was obtained in $\mathrm{Co}_{4} \mathrm{Sb}_{11.4} \mathrm{Te}_{0.6}$ at 820 $\mathrm{K} .{ }^{25}$ Duan et al. prepared $\mathrm{Co}_{4} \mathrm{Sb}_{12-\mathrm{x}} \mathrm{Te}_{\mathrm{x}}$ using solid state reaction and SPS, and found the nominal solubility limit was $x=0.6$ but the actual solubility limit was $x=0.272$ by EPMA measurement. ${ }^{20}$ Wojciechowski et al., however, indicated the actual solubility limit of Te was $x=0.24$ in $\mathrm{Co}_{4} \mathrm{Sb}_{12}$ ${ }_{\mathrm{x}} \mathrm{Te}_{\mathrm{x}}{ }^{26}$ For Se doped $\mathrm{CoSb}_{3}$, Wojciechowski et al. suggested that Se substituted the Sb site in $\mathrm{CoSb}_{3}$, which forms the $\mathrm{Co}_{4} \mathrm{Sb}_{12-\mathrm{x}} \mathrm{Se}_{\mathrm{x}}$ compound. ${ }^{26}$ Moreover, Duan et al. indicated that partial Se element would fill into the void center in Se and Te co-doped $\mathrm{CoSb}_{3}$, resulting in the formation of the $\mathrm{Se}_{\mathrm{y}-\mathrm{m}} \mathrm{Co}_{4} \mathrm{Sb}_{12-\mathrm{z}-\mathrm{m}} \mathrm{Te}_{\mathrm{z}} \mathrm{Se}_{\mathrm{m}}$ compound. ${ }^{17}$ For $\mathrm{S}$ doped $\mathrm{CoSb}_{3}$, Duan et al. indicated that elemental $\mathrm{S}$ can't go into the lattice framework, but would instead go into the void center in S and Te codoped $\mathrm{CoSb}_{3} .{ }^{17}$ For $\mathrm{O}$ doped $\mathrm{CoSb}_{3}$, Zhao et al. studied the high temperature oxidation behavior of $\mathrm{CoSb}_{3}$ in air and found the oxide scale of $\mathrm{CoSb}_{3}$ was the mixture of $\mathrm{Sb}_{2} \mathrm{O}_{3}$ and $\mathrm{CoSb}_{2} \mathrm{O}_{6}{ }^{27}$ Obviously, the defect thermodynamics of VIA-group element (Te, Se, S, O) doped $\mathrm{CoSb}_{3}$, including defect-controlled electronic structure, optimum carrier concentrations and solubility limitation, lacks of systematic study so far.

In order to determine the thermodynamics properties of VIA-group element $(\mathrm{O}, \mathrm{S}, \mathrm{Se}, \mathrm{Te})$ doped $\mathrm{CoSb}_{3}$, we applied density functional theory to investigate the point defect chemistry of these dopants in $\mathrm{CoSb}_{3}$. We found that these dopants lead to unusual (n- or p-type) conductivity behaviors in $\mathrm{CoSb}_{3}$. This can be explained by the breakage of $\mathrm{Sb}_{4}$-rings, which is similar to our previous intrinsic defect study of $\mathrm{CoSb}_{3}$. In single-atom-doped $\mathrm{CoSb}_{3}$, the dominant $\mathrm{O}$ interstitial $\left(\mathrm{O}_{\mathrm{i}}\right)$ defect chemically breaks the $\mathrm{Sb}_{4}$-ring and meanwhile forms an interesting O-4Sb fivemembered ring, leading to a neutral behavior of $\mathrm{O}_{\mathrm{i}}$, which agrees with the charged defect formation energy calculation. In double-atom-doped $\mathrm{CoSb}_{3}, \mathrm{~S}$ interstitials $\left(\mathrm{S}_{\mathrm{i}}\right)$ can stably form and collapse the Te-3Sb four-membered ring within Te doped $\mathrm{CoSb}_{3}$, leading to a p-type conduction behavior and the formation of lone pairs of Te $p$ orbitals, which well explains the previous experimental reports that $\mathrm{S}$ filler decreased the electron carrier concentration and thermal conductivity within Te doped $\mathrm{CoSb}_{3} .{ }^{17}$ The calculated electron carrier concentration of Te doping is higher compared with that of Se and S doping. The predicted phase diagram shows that $\mathrm{S}$ has a larger solubility within $\mathrm{CoSb}_{3-\mathrm{y}} \mathrm{Te}_{\mathrm{y}}$ system than that in the system without Te doping. We believe that the results presented in this theoretical study may stimulate further experimental research to optimize the electronic and thermal properties of the skutterudite $\mathrm{CoSb}_{3}$ phase as high-performance bulk TE material. 


\section{METHODOLOGY}

All density functional theory (DFT) calculations were carried out within the Vienna ab initio Simulation Package (VASP) using the projector augmented wave (PAW) method with the Perdew-Burke-Ernzerhof (PBE) generalized gradient approximation (GGA) exchange-correlation functional. ${ }^{28-30}$ The $3 s^{2} 3 p^{6} 3 d^{8} 4 s^{1}$ electrons of $\mathrm{Co}, 5 s^{2} 5 p^{3}$ electrons of $\mathrm{Sb}, 2 s^{2} 2 p^{4}$ electrons of $\mathrm{O}$, $3 s^{2} 3 p^{4}$ electrons of S, $4 s^{2} 4 p^{4}$ electrons of Se, and $5 s^{2} 5 p^{4}$ electrons of Te were treated as valence states to generate the PAW potentials. The defect structure calculations of $\mathrm{O}, \mathrm{S}, \mathrm{Se}$, and Te doped $\mathrm{CoSb}_{3}$ were performed on a cubic cell containing 32 atoms with a $k$-point grid set of $7 \times 7 \times 7$ Monkhorst-Pack scheme. All charged defect calculations were performed on a $2 \times 2 \times 2$ supercell of the cubic unit cell that contained 256 atoms. The gamma only $k$-point sampling is used for all the supercells. Spin polarization is performed for all calculations. The convergence setups are similar with our prior work on intrinsic defect calculations. ${ }^{31}$

\section{RESULTS AND DISCUSSION}

\subsection{Crystal structure of $\mathrm{CoSb}_{3}$}

The skutterudite $\mathrm{CoSb}_{3}$ is a body-centered cubic material crystallizing in the space group Im3 (204), as shown in Figure 1. The cubic unit cell contains 8 Co and $24 \mathrm{Sb}$ atoms occupying the $8 c$ - and the $24 g$-sites, respectively. ${ }^{31}$ In the unit cell, the Co atomic framework forms eight smaller cubes six of which are centered by $\mathrm{Sb}_{4}$-rings, while the other two remain empty.

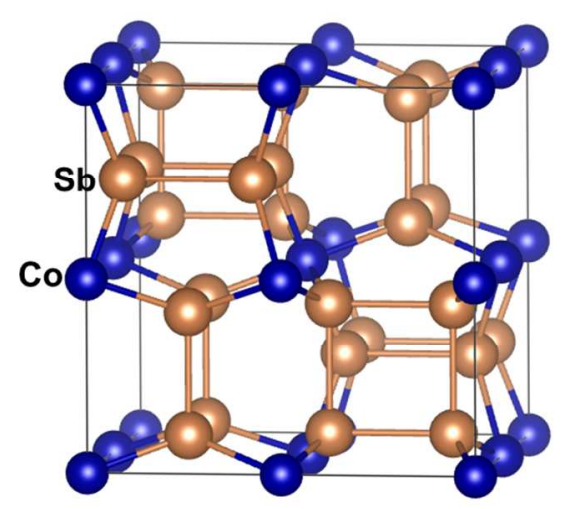

Figure 1. The crystal structure of $\mathrm{CoSb}_{3}$ with $\mathrm{Sb}_{4}$ rings. The $\mathrm{Co}$ and $\mathrm{Sb}$ atoms are represented with blue and brown colors, respectively. 


\subsection{Point defect structure and defect formation energy}

The formation energies of VIA-group (Te, Se, S, O) doped $\mathrm{CoSb}_{3}$ are systematically investigated to determine the stable point defect structures and ( $\mathrm{n}$ - or p-type) conductivity behavior. The formation energy of a defect $D$ with a charge state $q$ is written as, ${ }^{32}$

$$
\Delta H_{D, q}=E_{D, q}-E_{0}-\sum_{i} n_{i} \mu_{i}+q\left(E_{v}+\Delta E_{p a}+E_{F}\right)+\Delta E_{i c}
$$

where $E_{D, q}$ is the total energy of the defect structure $D$, and $E_{0}$ is the total energy of the ideal cell. The integer $n_{i}$ represents the number of atoms of type $i$ (host atoms or impurity atoms) which have been added to $\left(n_{i}>0\right)$ or removed from $\left(n_{i}<0\right)$ the supercell to form the defect, and $\mu_{i}$ are the atomic chemical potentials corresponding to this change. The atomic chemical potential $\mu_{i}$ is thermodynamically defined as a measure of free energy changes when some atoms $\left(n_{i}\right)$ are removed from $\left(n_{i}<0\right)$ or added to $\left(n_{i}>0\right)$ the system. ${ }^{32} E_{v}$ is the eigenvalue of the valence band maximum (VBM) of the ideal bulk, $E_{F}$ is the electron chemical potential (The electron chemical potential is defined as the Fermi level at $T=0$ ) referenced to the VBM. $\Delta E_{p a}$ and $\Delta E_{i c}$ are the potential alignment correction and image charge corrections in a charged supercell, respectively. 33,34

Here, we also investigate the formation of complex defects. The binding energy is defined to consider the formation of a complex defect, ${ }^{35}$

$$
E_{b}\left(D_{A}+D_{B}\right)=\Delta H\left(D_{A}\right)+\Delta H\left(D_{B}\right)-\Delta H\left(D_{A}+D_{B}\right)
$$

where $\Delta H\left(D_{A}\right)$ and $\Delta H\left(D_{B}\right)$ are the formation energies of a single point defect $D_{A}$ and $D_{B}$, respectively, $\Delta H\left(D_{A}+D_{B}\right)$ is the formation energy of a complex $D_{A}+D_{B}, E_{b}\left(D_{A}+D_{B}\right)$ is the binding energy of a complex $D_{A}+D_{B}$. A positive binding energy corresponds to defect complexes forming, which are more favorably than single defects.

Three typical extrinsic single point defect sites are considered for $M(M=\mathrm{O}, \mathrm{S}, \mathrm{Se}, \mathrm{Te})$ doped $\mathrm{CoSb}_{3}: M_{\mathrm{i}-7}$ ( $M$ interstitial with 7-fold coordination) ${ }^{31} M_{\mathrm{i}-\mathrm{v}}$ ( $M$ interstitial in the void center), and $M_{\mathrm{Sb}}(M$ substituting $\mathrm{Sb})$, as shown in Figure $\mathrm{S} 1$ in the supporting information. $\mathrm{Co}, \mathrm{Sb}$, and $M$ $(M=\mathrm{O}, \mathrm{S}, \mathrm{Se}, \mathrm{Te})$ are group 9, 15, and 16 elements, respectively. Obviously, atom $M$ and $\mathrm{Sb}$ as p-block elements have similar elemental properties allowing for $M_{\mathrm{Sb}}$ type defects to form much easier than $M_{\mathrm{Co}}$ type defects. All the experimental results show $\mathrm{Te}_{\mathrm{Sb}}$ or $\mathrm{Se}_{\mathrm{Sb}}$ are easier to form than 
$\mathrm{Te}_{\mathrm{Co}}$ or $\mathrm{Se}_{\mathrm{Co}}$ in Te or Se doped $\mathrm{CoSb}_{3} \cdot{ }^{17,18,20,25,26}$ In addition, our intrinsic defect study reveals that $\mathrm{Sb}_{\mathrm{Co}}$ has a high formation energy of $\sim 3 \mathrm{eV}$ in the Co rich region, ${ }^{31}$ suggesting $\mathrm{Sb}_{\mathrm{Co}}$ is very unstable and indeed hard to form. Thus, we didn't investigate $M_{\mathrm{Co}}$ in this work. We firstly examined the atomic structure of interstitial $M\left(M_{\mathrm{i}}\right)$ because of two possible interstitial sites in $\mathrm{CoSb}_{3}\left(M_{\mathrm{i}-7}\right.$ and $\left.M_{\mathrm{i}-\mathrm{V}}\right)$. The calculated free energy of the neutral $\mathrm{O}_{\mathrm{i}-7}$ structure in the cubic cell is $2.79 \mathrm{eV}$ lower than that of the $\mathrm{O}_{\mathrm{i}-\mathrm{v}}$ structure, indicating the $\mathrm{O}_{\mathrm{i}-7}$ is the stable $\mathrm{O}$ interstitial site. The free energy of the neutral $M_{\mathrm{i}-\mathrm{v}}$ is found to be $0.59,0.95$, and $1.28 \mathrm{eV}$ lower than that of the $M_{\mathrm{i}-7}$ structure for $M=\mathrm{S}, \mathrm{Se}, \mathrm{Te}$, respectively, indicating the $M_{\mathrm{i}-\mathrm{v}}$ is the stable interstitial site for $M=\mathrm{S}$, Se, Te. Thus, the $\mathrm{O}_{\mathrm{i}-7}$ and $M_{\mathrm{i}-\mathrm{v}}(M=\mathrm{S}, \mathrm{Se}, \mathrm{Te})$, structures are chosen for the charged defect formation energy calculations.

Meanwhile, two kinds of complex defects are considered in $\mathrm{S}$ and Te co-doped $\mathrm{CoSb}_{3}$ : $\mathrm{S}_{\mathrm{Sb}}+\mathrm{Te}_{\mathrm{Sb}}$ and $\mathrm{S}_{\mathrm{i}}+\mathrm{Te}_{\mathrm{Sb}}$, as depicted in Figures $\mathrm{S} 2$ and $\mathrm{S} 3$. In the $\mathrm{S}_{\mathrm{Sb}}+\mathrm{Te}_{\mathrm{Sb}}$ structure it is found that a placement of $\mathrm{S}$ and Te that brings about the longer bond of $3.016 \AA$ has a $0.36 \mathrm{eV}$ lower free energy compared to a placement that results in the shorter bond of 2.886. In the $\mathrm{S}_{\mathrm{i}}+\mathrm{Te}_{\mathrm{Sb}}$ structure it is found that the $\mathrm{S}$ filler atom in plane with the Te-3Sb-ring results in $0.35 \mathrm{eV}$ reduction in free energy compared to if $\mathrm{S}$ atom is out of plane. Thus, the structures in Figures S2(a) and S3(a) are chosen to perform the charged defect formation energy calculations.

The charged defect formation energies of the above various structures as a function of Fermi energy $\left(E_{F}\right)$ for both Co rich and $\mathrm{Sb}$ rich regions, calculated by Eqn. (1), are shown in Figure 2. Here, we also examine the possibility of $\mathrm{Se}_{\mathrm{i}}+\mathrm{Se}_{\mathrm{Sb}}, \mathrm{Se}_{\mathrm{Sb}}+\mathrm{Te}_{\mathrm{Sb}}$ and $\mathrm{Se}_{\mathrm{i}}+\mathrm{Te}_{\mathrm{Sb}}$ formation in Se doped and $\mathrm{Se}+\mathrm{Te}$ co-doped $\mathrm{CoSb}_{3}$, respectively. Various charged states were calculated for all defects. The slope of the curve represents the charge state of each defect. For $M$ doped $\mathrm{CoSb}_{3}$, the Co rich region corresponds to the presence of $\mathrm{Sb}_{2} M_{3}, \mathrm{CoSb}_{2}$, and $\mathrm{CoSb}_{3}$, whereas the $\mathrm{Sb}$ rich region corresponds to the presence of $\mathrm{Sb}_{2} M_{3}, \mathrm{CoSb}_{3}$, and $\mathrm{Sb}$. The n-type point defect means the impurity donates electrons to the system, leading to the positive charge state. Similarly, the p-type defect means the impurity accepts electrons from the system, leading to the negative charge state. The neutral defect corresponds to the zero charge state.

In $\mathrm{O}$ doped $\mathrm{CoSb}_{3}$, the formation energy of the neutral $\mathrm{O}_{\mathrm{i}}$ defect in the band gap is much lower than the $\mathrm{O}_{\mathrm{Sb}}$ defect with a -1 charge state both in Co rich and $\mathrm{Sb}$ rich regions as shown in Figure 2(a) and (b), indicating the $\mathrm{O}_{\mathrm{i}}$ is the dominant neutral defect. It is widely known that $\mathrm{O}$ reacts with $\mathrm{Sb}$, leading to the second phase formation of $\mathrm{Sb}_{2} \mathrm{O}_{3}$, or $\mathrm{CoSb}_{2} \mathrm{O}_{6}$ in $\mathrm{CoSb}_{3}{ }^{27}$ Our study shows that $\mathrm{O}_{\mathrm{i}}$ will form in $\mathrm{CoSb}_{3}$, which is not a contradiction. When the amount of impurity $\mathrm{O}$ is small, the impurity $\mathrm{O}$ may go into the lattice of $\mathrm{CoSb}_{3}$ and form $\mathrm{O}_{\mathrm{i}}$. When reaching the doping (solubility) limit, excess $\mathrm{O}$ may react with $\mathrm{Sb}$, which leads to the formation of $\mathrm{Sb}_{2} \mathrm{O}_{3}$ or $\mathrm{CoSb}_{2} \mathrm{O}_{6}$ 
as secondary phases. ${ }^{27}$ In $\mathrm{S}$ doped $\mathrm{CoSb}_{3}, \mathrm{~S}_{\mathrm{Sb}}$ with a +1 charge state is the dominant defect in the band gap region for a Co rich system. In the $\mathrm{Sb}$ rich region, $\mathrm{S}_{\mathrm{Sb}}$ with a +1 charge state and $\mathrm{S}_{\mathrm{i}}$ with a -2 charge state co-dominate the defect type. However, the calculated equilibrium Fermi level range of $\mathrm{S}$ doping as shown in Figure $4(\mathrm{~b})$ suggests that $\mathrm{S}_{\mathrm{Sb}}$ with a +1 charge state is still the dominant defect in the $\mathrm{Sb}$ rich region. In $M(M=\mathrm{Se}, \mathrm{Te})$ doped $\mathrm{CoSb}_{3}$, the $M_{\mathrm{Sb}}$ defect with a +1 charge state has a much lower formation energy compared with the $M_{\mathrm{i}}$ defect with a -2 charge state in the band gap as shown in Figure 2(e)-(h), suggesting the $M_{\mathrm{Sb}}$ dominates the n-type single point defect both in Co rich and $\mathrm{Sb}$ rich regions. It is noted that the formation energy of $\mathrm{Te}_{\mathrm{Sb}}$ with $\mathrm{a}+1$ charge state is lower than that of $\mathrm{Se}_{\mathrm{Sb}}$, and much lower than that of $\mathrm{S}_{\mathrm{Sb}}$, implying that $\mathrm{Te}_{\mathrm{Sb}}$ is easier to form than $\mathrm{Se}_{\mathrm{Sb}}$, and much easier to form than $\mathrm{S}_{\mathrm{Sb}}$. This can be attributed to the degree of (Pauling) electronegativity between $M$ atom and $\mathrm{Sb}$ atom of $\mathrm{S}(2.58)>\mathrm{Se}(2.55)>\mathrm{Te}(2.10)>\mathrm{Sb}$ (2.05), and the atomic radius difference of $\mathrm{S}(1.02 \AA)<\mathrm{Se}(1.16 \AA)<\mathrm{Te}(1.35 \AA)<\mathrm{Sb}(1.38 \AA)$.

Here, each complex defect considered shows a positive binding energy both in Co rich and $\mathrm{Sb}$ rich regions as listed in Table 1, suggesting these defects are all favorable. In $\mathrm{S}+\mathrm{Te}$ co-doped $\mathrm{CoSb}_{3}$, the $\mathrm{S}_{\mathrm{i}}+\mathrm{Te}_{\mathrm{Sb}}$ complex defect with a -1 charge state has a lower formation energy than the neutral $\mathrm{S}_{\mathrm{Sb}}+\mathrm{Te}_{\mathrm{Sb}}$ complex defect both in Co rich and $\mathrm{Sb}$ rich regions (See Figure 2(c) and 2(d)), indicating that $\mathrm{S}_{\mathrm{i}}+\mathrm{Te}_{\mathrm{Sb}}$ is the stable p-type defect, which agrees well with previous theoretical prediction that a $\mathrm{S}$ filler can be a stable formulation within Te doped $\mathrm{CoSb}_{3} \cdot{ }^{17}$ Furthermore, the revealed p-type character of $\mathrm{S}$ filler leads to decreased electron carrier concentration in Te doped $\mathrm{CoSb}_{3}$, explaining the experimental observation that the electron carrier concentration of $\mathrm{S}_{0.19} \mathrm{Co}_{4} \mathrm{Sb}_{11.42} \mathrm{Te}_{0.52}\left(-1.9 \times 10^{20} \mathrm{~cm}^{-3}\right)$ is much lower than that of $\mathrm{Co}_{4} \mathrm{Sb}_{11.46} \mathrm{Te}_{0.43}\left(-5.6 \times 10^{20} \mathrm{~cm}^{-3}\right){ }^{17}$ In $\mathrm{Se}+\mathrm{Te}$ co-doped $\mathrm{CoSb}_{3}$, the formation energy of the neutral $\mathrm{Se}_{\mathrm{Sb}}+\mathrm{Te}_{\mathrm{Sb}}$ defect is much lower than that of the $\mathrm{Se}_{\mathrm{i}}+\mathrm{Te}_{\mathrm{Sb}}$ defect with a -1 charge state in the Co rich region (Figure 2(e)), suggesting that the $\mathrm{Se}_{\mathrm{Sb}}+\mathrm{Te}_{\mathrm{Sb}}$ defect would form in the Co rich region. However, the $\mathrm{Se}_{\mathrm{i}}+\mathrm{Te}_{\mathrm{Sb}}$ defect forms in the $\mathrm{Sb}$ rich region because $\mathrm{Se}_{\mathrm{i}}+\mathrm{Te}_{\mathrm{Sb}}$ has a lower formation energy than $\mathrm{Se}_{\mathrm{Sb}}+\mathrm{Te}_{\mathrm{Sb}}$ near the conduction band region, as displayed in Figure 2(f). In addition, the positive binding energy of $\mathrm{Se}_{\mathrm{i}}+\mathrm{Se}_{\mathrm{Sb}}$ defect (0.908 and $0.892 \mathrm{eV}$ in $\mathrm{Co}$ rich and $\mathrm{Sb}$ rich region, respectively) indicates $\mathrm{Se}_{\mathrm{i}}+\mathrm{Se}_{\mathrm{Sb}}$ is more stable compared with the separated $\mathrm{Se}_{\mathrm{i}}$ and $\mathrm{Se}_{\mathrm{Sb}}$ defects. Very recently, by using the annular bright field scanning transmission electron microscopy (ABF-STEM) technique, an experimental study confirmed that the impurity Se is located in the cages in Sefilled $\mathrm{Se}_{0.17-\mathrm{m}} \mathrm{Co}_{4} \mathrm{Sb}_{11.31} \mathrm{Te}_{0.53} \mathrm{Se}_{\mathrm{m}}$, ${ }^{17}$ which agrees well with our theoretical prediction. 

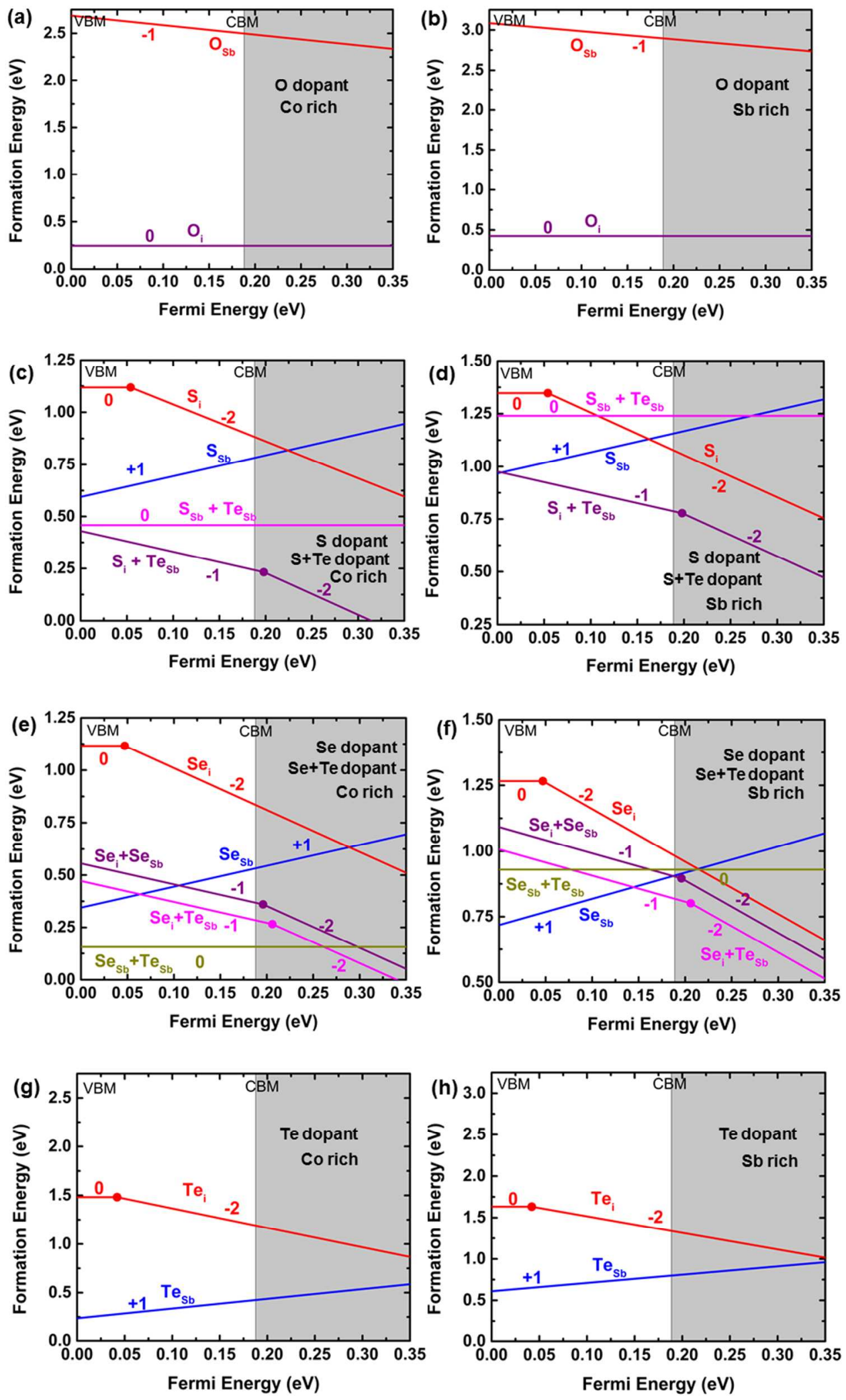

8 
Figure 2. Calculated defect formation energies as a function of Fermi energy: (a) $\mathrm{O}$ doped $\mathrm{CoSb}_{3}$ in Co rich region, (b) $\mathrm{O}$ doped $\mathrm{CoSb}_{3}$ in $\mathrm{Sb}$ rich region, (c) $\mathrm{S}$ and $\mathrm{S}+\mathrm{Te}$ doped $\mathrm{CoSb}_{3}$ in Co rich region, (d) $\mathrm{S}$ and $\mathrm{Se}+\mathrm{Te}$ doped $\mathrm{CoSb}_{3}$ in $\mathrm{Sb}$ rich region, (e) Se and $\mathrm{Se}+\mathrm{Te}$ doped $\mathrm{CoSb}_{3}$ in Co rich region, (f) $\mathrm{Se}$ and $\mathrm{Se}+\mathrm{Te}$ doped $\mathrm{CoSb}_{3}$ in $\mathrm{Sb}$ rich region, (c) Te doped $\mathrm{CoSb}_{3}$ in Co rich region, (c) Te doped $\mathrm{CoSb}_{3}$ in $\mathrm{Sb}$ rich region. The slope of the curve represents the charge state of each defect. The white area represents the band gap region. The zero Fermi energy corresponds to the VBM.

Table 1. The binding energy (in eV) calculated for each complex defect considered in the $\mathrm{S}+\mathrm{Te}$ and $\mathrm{Se}+\mathrm{Te}$ co-doped $\mathrm{CoSb}_{3}$ system, respectively.

\begin{tabular}{cccccc}
\hline \hline & $\mathrm{S}_{\mathrm{i}}+\mathrm{Te}_{\mathrm{Sb}}$ & $\mathrm{S}_{\mathrm{Sb}}+\mathrm{Te}_{\mathrm{Sb}}$ & $\mathrm{Se}_{\mathrm{i}}+\mathrm{Se}_{\mathrm{Sb}}$ & $\mathrm{Se}_{\mathrm{Sb}}+\mathrm{Te}_{\mathrm{Sb}}$ & $\mathrm{Se}_{\mathrm{i}}+\mathrm{Te}_{\mathrm{Sb}}$ \\
\hline Co rich & 0.994 & 0.373 & 0.908 & 0.426 & 0.882 \\
Sb rich & 0.949 & 0.337 & 0.892 & 0.398 & 0.868 \\
\hline \hline
\end{tabular}

\subsection{Atomistic explanation of extrinsic defects in $M(M=\mathrm{O}, \mathrm{S}, \mathrm{Se}, \mathrm{Te})$ doped $\mathrm{CoSb}_{3}$}

The stable atomic configuration of the $\mathrm{O}_{\mathrm{i}}$ defect shows that the $\mathrm{O}_{\mathrm{i}}$ atom chemically breaks the $\mathrm{Sb}_{4}$-ring with the $\mathrm{Sb}-\mathrm{Sb}$ atomic distance of $3.753 \AA$, and forms an interesting O-4Sb fivemembered ring with two regenerated O-Sb bonds, as shown in Figure 3(a). The bond length of $\mathrm{O}-\mathrm{Sb}$ bond is $1.988 \AA$. This value is consistent with the covalent radii of $\sim 1.977 \AA$ between O and $\mathrm{Sb}$ observed in $\mathrm{Sb}_{2} \mathrm{O}_{3}{ }^{36}$ The breakage of the $\mathrm{Sb}-\mathrm{Sb} \sigma$-type bond moves down the $\mathrm{Sb}-\mathrm{Sb}$ antibonding states to produce 2 new lone pairs that require 2 additional electrons, as described in our previous study. ${ }^{31}$ The two new O-Sb covalent bonds generate two shared electron pairs (4 electrons). These bonds provide 2 electrons to the two $\mathrm{Sb}$ atoms, compensating for the loss of the bond between then, and also provide 2 additional electrons to chemically saturate the $\mathrm{O}_{\mathrm{i}}$ atom with valence $\mathrm{O}^{2-}$. Thus, the $\mathrm{O}_{\mathrm{i}}$ induced formation of $\mathrm{O}-4 \mathrm{Sb}$ five-membered ring can self-balance its charge state, making the $\mathrm{O}_{\mathrm{i}}$ a neutral defect, which agrees with our defect formation energy calculation as shown in Figure 2(a) and 2(b).

The point defect $M_{\mathrm{Sb}}(M=\mathrm{S}, \mathrm{Se}, \mathrm{Te})$ slightly changes the local atomic structure in noncomplex doped $\mathrm{CoSb}_{3}$, as shown in Figure 3(b). After relaxing the structure, the $M$-3Sb-ring structure remains, with the bond lengths for the $M-\mathrm{Sb}$ bond changed to 2.750 and $3.116 \AA$ for $M$ $=\mathrm{S}, 2.827$ and $3.075 \AA$ for $M=\mathrm{Se}, 2.924$ and $3.107 \AA$ for $M=$ Te. The VIA-group elements $M$ $\left(s^{2} p^{4}\right)$ have one more valence electron than $\mathrm{Sb}\left(s^{2} p^{3}\right)$. Therefore, these $M_{\mathrm{Sb}}$ must donate 1 electron 
to the system, leading to $M_{\mathrm{Sb}}$ as a donor impurity with a +1 charge state, agreeing with the defect formation energy results as shown in Figure 2(c)-2(h).

The complex defect $\mathrm{S}_{\mathrm{Sb}}+\mathrm{Te}_{\mathrm{Sb}}$ breaks the $\mathrm{S}-\mathrm{Te}$ bond (3.697 $\AA$ ) and collapses the Te-S-2Sb four-membered ring, as displayed in Figure 3(c). The breakage of the S-Te bond produces 2 lone pairs which require 2 additional electrons from the system. $\mathrm{S}_{\mathrm{Sb}}+\mathrm{Te}_{\mathrm{Sb}}$ can provide 2 additional electrons to the system because $\mathrm{S}$ and Te both have one more valence electron than $\mathrm{Sb}$ as discussed above, which balances the charge state of this collapsed S-Te-2Sb four-membered ring. Thus, $\mathrm{S}_{\mathrm{Sb}}+\mathrm{Te}_{\mathrm{Sb}}$ is a neutral defect, which is consistent with our charged formation energy calculation in Figure 2(c) and 2(d). Changing $\mathrm{S}$ to Se in $\mathrm{Se}_{\mathrm{Sb}}+\mathrm{Te}_{\mathrm{Sb}}$, Figure 3(e), we see the breakage of the Se-Te bond indicated by the long distance of $3.310 \AA$ and the collapse of the Se$\mathrm{Te}-2 \mathrm{Sb}$ four-membered ring. This once more leads to an overall neutral defect, which is again consistent with the calculated charged formation energy in Figure 2(e) and 2(f).

The complex defect $\mathrm{S}_{\mathrm{i}}+\mathrm{Te}_{\mathrm{Sb}}$ dramatically breaks the Te-3Sb four-membered ring indicated by the $\mathrm{Te}-\mathrm{Sb}$ atomic distance of $3.489 \AA$ and generates a new S-Sb bond, as shown in Figure 3(d). The bond length of $\mathrm{S}-\mathrm{Sb}$ bond is $2.609 \AA$, which is close to the covalent radii $(\sim 2.585 \AA)$ between $\mathrm{S}$ and $\mathrm{Sb}$, as observed in $\mathrm{AgSbS}_{2}{ }^{37}$ The breakage of the Te-Sb bond requires 2 electrons from the system, and the $S_{i}$ atom chemically behaves as valence $S^{2-}$, which also requires 2 electrons from the system. The new S-Sb covalent bond only generates one shared electron pair, which donates 2 electrons to the system, and $\mathrm{Te}_{\mathrm{Sb}}$ can donate 1 electron to the system. Combined, the complex defect $\mathrm{S}_{\mathrm{i}}+\mathrm{Te} \mathrm{e}_{\mathrm{Sb}}$ requires 1 more electron from the system, which leads to $\mathrm{S}_{\mathrm{i}}+\mathrm{Te}_{\mathrm{Sb}}$ as an acceptor complex defect with a - 1 charge state, explaining the charged defect formation energy as shown in Figure 2(c) and 2(d). A S filler atom within the Te doped $\mathrm{CoSb}_{3}$ leads to the formation of Te-3Sb-S chain structure and lone pairs of Te $p$ orbitals, which is similar with the Se-Sn-Se-Sn-Se chain structure in SnSe crystals. ${ }^{38}$ This explains the extremely low thermal conductivity in $\mathrm{S}+\mathrm{Te}$ doped $\mathrm{CoSb}_{3}$ as observed in the previous experiment reports. ${ }^{17}$

Similarly, as shown in Figure 3(f), the presence of $\mathrm{Se}_{\mathrm{i}}+\mathrm{Te}_{\mathrm{Sb}}$ breaks the Te-3Sb fourmembered ring, and a new covalent $\mathrm{Se}-\mathrm{Sb}$ bond is generated with the length of $2.808 \AA$ in the $\mathrm{Se}_{\mathrm{i}}+\mathrm{Te}_{\mathrm{Sb}}$ structure. This value is consistence with the radii $(\sim 2.777 \AA)$ between $\mathrm{Se}$ and $\mathrm{Sb}$ in $\mathrm{Sb}_{2} \mathrm{Se}_{3}{ }^{39}$ As discussed above, $\mathrm{Se}_{i}+\mathrm{Te}_{\mathrm{Sb}}$ is a p-type complex defect with a -1 charge state, which agrees with the charged defect formation energy as shown in Figure 2(e) and 2(f). 
(a)

$\mathrm{O}_{\mathrm{i}}$
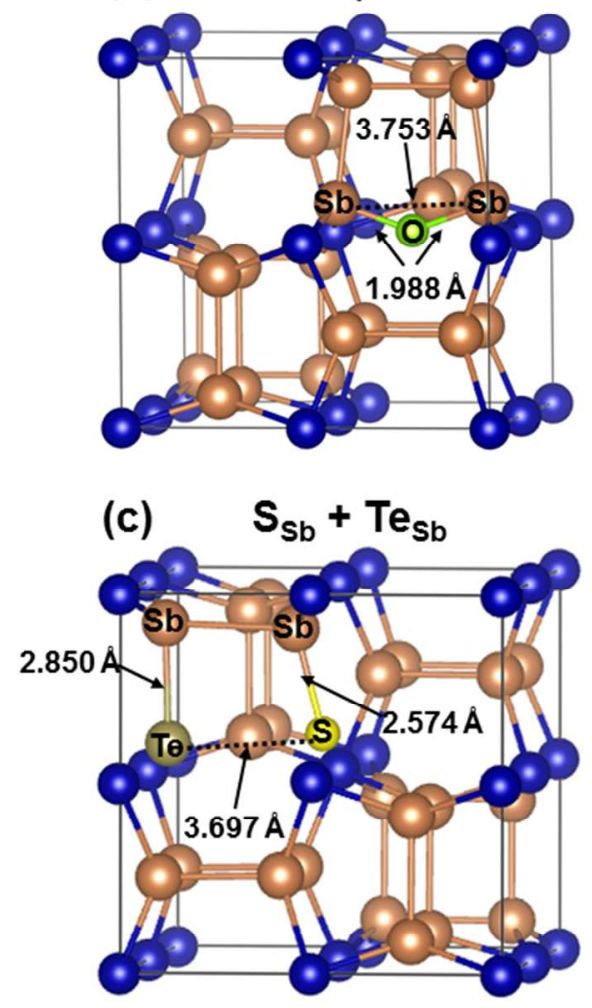

(e) $\mathrm{Se}_{\mathrm{sb}}+\mathrm{Te} \mathrm{e}_{\mathrm{sb}}$

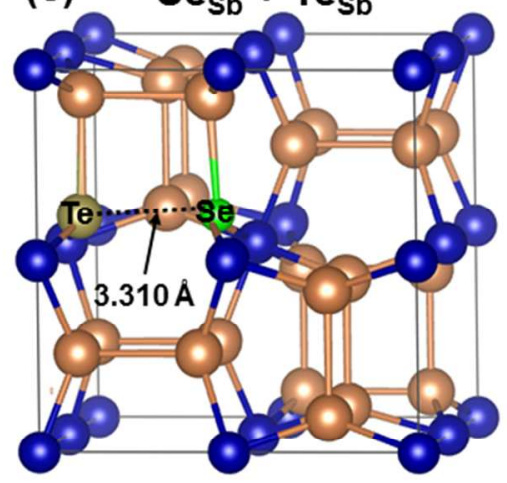

(b) $M_{\mathrm{Sb}}(M=\mathrm{S}, \mathrm{Se}, \mathrm{Te})$

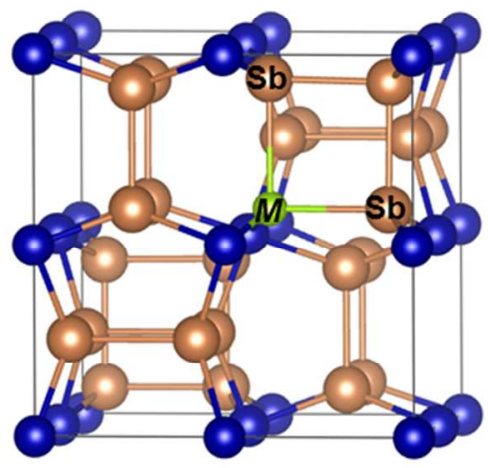

(d) $\mathrm{s}_{\mathrm{i}}+\mathrm{Te} \mathrm{e}_{\mathrm{sb}}$

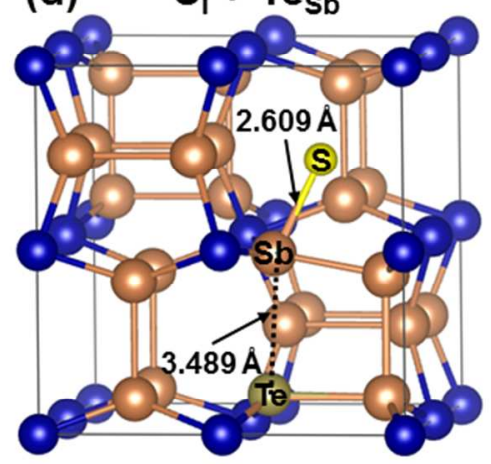

(f)

$\mathrm{Se}_{\mathrm{i}}+\mathrm{Te}_{\mathrm{sb}}$

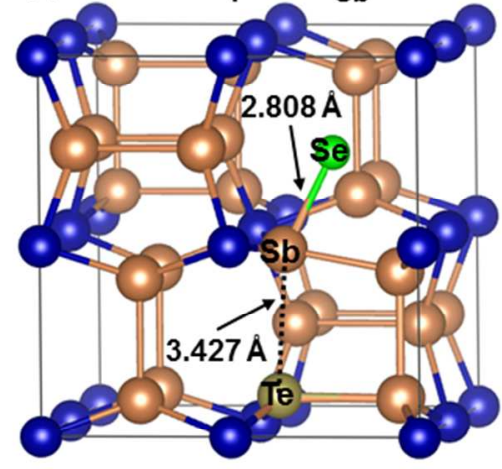

Figure 3. Local atomic structure of neutral $M(M=\mathrm{O}, \mathrm{S}, \mathrm{Se}, \mathrm{Te})$ doped $\mathrm{Co}_{64} \mathrm{Sb}_{192}$ after relaxation: (a) The $\mathrm{O}_{\mathrm{i}}$ structure after relaxation with the $\mathrm{O}-\mathrm{Sb}$ bond length of $1.988 \AA$. The long atomistic distance of $3.753 \AA$ represents the breakage of the $\mathrm{Sb}-\mathrm{Sb}$ bond, as observed in our previous study. ${ }^{31}$ The $M$ atom is represented with the green color. (b) The $M_{\mathrm{Sb}}(M=\mathrm{S}, \mathrm{Se}, \mathrm{Te})$ structure after relaxation with the $M$-Sb bond lengths of 2.750 and $3.116 \AA$ for $M=\mathrm{S}, 2.827$ and $3.075 \AA$ for $M=\mathrm{Se}, 2.924$ and $3.107 \AA$ for $M=\mathrm{Te}$, respectively. The $M$ atom is represented with the green color. (c) The $\mathrm{S}_{\mathrm{Sb}}+\mathrm{Te}_{\mathrm{Sb}}$ structure after relaxation with the $\mathrm{S}-\mathrm{Sb}$ and $\mathrm{Te}-\mathrm{Sb}$ bond lengths of 2.574 and $2.850 \AA$, respectively. The long atomistic distance of $3.697 \AA$ represents the breakage of the $\mathrm{S}-\mathrm{Te}$ bond. The $\mathrm{S}$ and Te atoms are represented with the yellow and brown 
colors, respectively. (d) The $\mathrm{S}_{\mathrm{i}}+\mathrm{Te}_{\mathrm{Sb}}$ structure after relaxation with the $\mathrm{S}-\mathrm{Sb}$ bond length of $2.609 \AA$. The long atomistic distance of $3.489 \AA$ represents the breakage of the Te-Sb bond. (e) $\mathrm{The}_{\mathrm{Sb}}+\mathrm{Te}_{\mathrm{Sb}}$ structure after relaxation. The long atomistic distance of $3.310 \AA$ represents the breakage of the Se-Te bond. The Se and $\mathrm{Te}$ atoms are represented with the yellow and brown colors, respectively. (f) $\mathrm{The}_{\mathrm{Se}}+\mathrm{Te}_{\mathrm{sb}}$ structure after relaxation with the $\mathrm{Se}-\mathrm{Sb}$ bond length of $2.808 \AA$. The long atomistic distance of $3.427 \AA$ represents the breakage of the $\mathrm{Te}-\mathrm{Sb}$ bond.

\subsection{Defect carrier concentration and solubility limitation in $M(M=O, S$, Se, Te $)$ doped $\mathrm{CoSb}_{3}$}

Calculated free carriers and predicted solubility limitation are helpful to optimize a material's carrier concentration and prepare a single-phase material, hence improving a material's thermoelectric properties in the thermoelectric semiconductors.

The defect concentration $c_{D, q}$ in the dilute limit is given by:

$$
c_{D, q}=N_{\text {site }} \exp \left(-\frac{\Delta H_{D, q}-T \Delta S}{k T}\right)
$$

where $\Delta H_{D, q}$ is the formation energy of a defect $D$ in a charge state $q$, which is calculated by Eqn. (1). $N_{\text {site }}$ is the concentration of possible defect sites determined by the multiplicity of the defect's Wyckoff site. $\Delta S$ is the configurational entropy change, which can be estimated by: ${ }^{40}$

$$
\Delta S=k\left\{\ln \left[N_{D}\left(N_{D}-1\right)\right]-\ln \left(2 N_{D}\right)\right\}
$$

where $N_{D}$ is the number of available sites in a fixed concentration of a specific defect. $T$ is the temperature and $k$ is the Boltzmann constant.

Charge neutrality requires:

$$
\sum_{D} \sum_{q} q c_{D, q}-n+p=0
$$

where $n$ and $p$ are the free carrier concentrations of electrons and holes defined by: ${ }^{41}$

$$
\begin{gathered}
n=\int_{E_{v}}^{+\infty} g(E) f\left(E ; E_{F}, T\right) d E \\
p=\int_{-\infty}^{E_{c}} g(E)\left[1-f\left(E ; E_{F}, T\right)\right] d E
\end{gathered}
$$

$g(E)$ is the density of states of ideal host cell, and $f\left(E ; E_{F}, T\right)$ is the Fermi-Dirac distribution given by: 
Following the procedure described above, the Fermi level $\left(E_{F}\right)$ and free carriers can be determined by iteratively solving the overall charge neutrality requirement, as displayed in Figures 4 and 5. In $\mathrm{O}$ doped $\mathrm{CoSb}_{3}$, because the dominant defect, $\mathrm{O}_{\mathrm{i}}$, is neutral, $E_{F}$ is exactly the same with that in intrinsic nonstoichiometric $\mathrm{CoSb}_{3} .{ }^{31}$ Here, it can be also concluded that the neutral $\mathrm{O}_{\mathrm{i}}$ doesn't change the free carriers of $\mathrm{CoSb}_{3}$. In Se doped $\mathrm{CoSb}_{3}, E_{F}$ slightly decreases with the increasing temperature in the Co rich region. The position of $E_{F}(\sim 0.1 \mathrm{eV}$ shown in Figure 4(a)) confirms that the single point defect $\mathrm{Se}_{\mathrm{Sb}}$ with $\mathrm{a}+1$ charge state is the dominant defect type compared with $\mathrm{Se}_{\mathrm{i}}+\mathrm{Se}_{\mathrm{Sb}}$ complex defect with a -1 charge state. Even though the formation energy of $\mathrm{Se}_{\mathrm{Sb}}$ in the Co rich region is much lower than that in the $\mathrm{Sb}$ rich region, the electron carrier concentration of Se doping in the Co rich region is comparable with that in the $\mathrm{Sb}$ rich region as shown in Figure 5(b). This can be attributed to the p-type character of $\mathrm{Se}_{\mathrm{i}}+\mathrm{Se}_{\mathrm{Sb}}$ complex defect. In $\mathrm{S}$, Te doped $\mathrm{CoSb}_{3}, E_{F}$ increases with the increasing temperature, and goes deeply into the conduction band for Te doping, leading to an n-type conduction behavior. This can also be confirmed by the calculated electron carrier concentration shown in Figures 5(a) and 8(c). $E_{F}$ and electron carrier concentration in the Co rich condition is much higher than that in the $\mathrm{Sb}$ rich condition at high temperature, resulting from the lower defect formation energy of $M_{\mathrm{Sb}}(M$ $=\mathrm{S}, \mathrm{Te}$ ) in the Co rich condition compared with that in the $\mathrm{Sb}$ rich region. $E_{F}$ and electron carrier concentration of Te doping are higher than that of $\mathrm{S}$ doping, as observed in Figures 4 and 5 , which can be explained by the minor (Pauling) electronegativity difference between Te (2.10) and $\mathrm{Sb}$ (2.05) atom. In $\mathrm{S}+\mathrm{Te}$ co-doped $\mathrm{CoSb}_{3}, E_{F}$ reduces and goes deeply into the valence band with the increasing temperature both in $\mathrm{Co}$ rich and $\mathrm{Sb}$ rich conditions, resulting in a strong p-type behavior. The calculated hole free carriers as shown in Figure 5(d) further confirms that S filler reduces the electron carrier concentration in Te doped $\mathrm{CoSb}_{3} .{ }^{17}$ The annealing temperature region of $\mathrm{CoSb}_{3}$ is generally around $850-1100 \mathrm{~K} .{ }^{14-23}$ The electron carrier concentration is found to be $10^{20}-10^{21} \mathrm{~cm}^{-3}$ in Te doped $\mathrm{CoSb}_{3}$ as depicted in Figure 4(c), which agrees well with the experimental reports. ${ }^{18,20,24,26}$ 

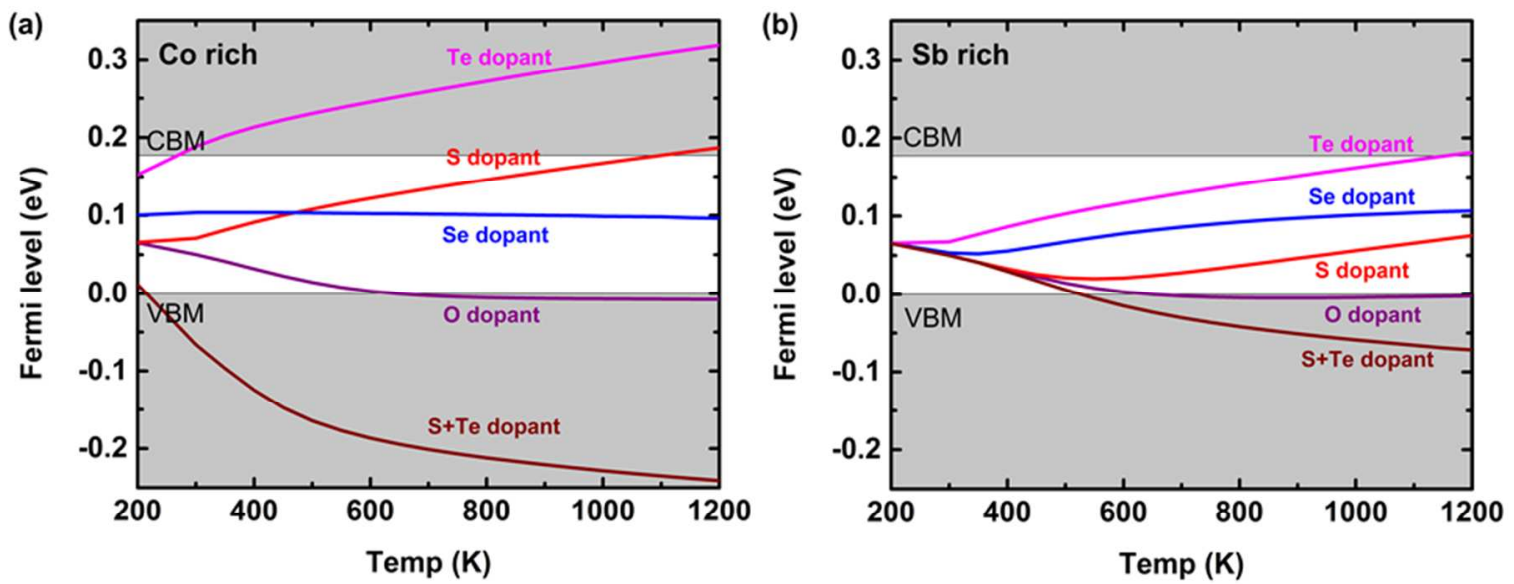

Figure 4. Calculated Fermi level $\left(E_{F}\right)$ as a function of temperature both in (a) Co rich and (b) Sb rich conditions.
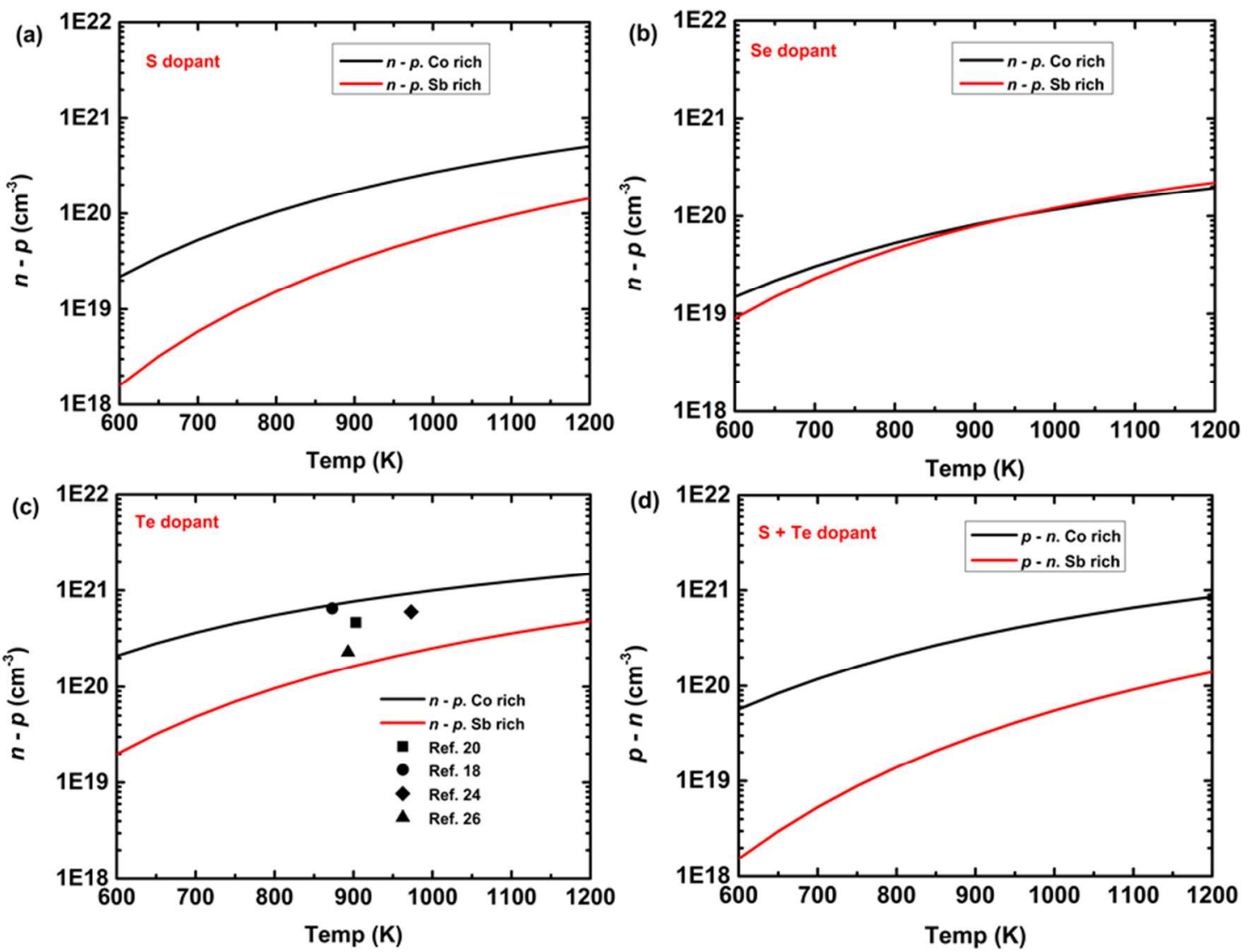

Figure 5. Calculated free carriers as a function of temperature in (a) $\mathrm{S}$ doped $\mathrm{CoSb}_{3}$, (b) Se doped $\mathrm{CoSb}_{3}$, (c) Se doped $\mathrm{CoSb}_{3}$, and (d) $\mathrm{S}+\mathrm{Te}$ co-doped $\mathrm{CoSb}_{3}$. The black and red line represents the Co rich and $\mathrm{Sb}$ 
rich condition, respectively. Reported experimental Hall carrier concentrations at different annealing temperature in Te doped $\mathrm{CoSb}_{3}$ system are displayed for comparison.

The total composition $x$ of a phase with defects within an equilibrium set of atomic chemical potentials can be calculated by:

$$
x=\frac{N_{0}^{i}+\Delta N^{i}}{\sum_{i}\left(N_{0}^{i}+\Delta N^{i}\right)}
$$

where $N_{0}^{i}$ is the stoichiometric number of atoms of $i(i=\mathrm{Co}, \mathrm{Sb}, M)$ in $M(M=\mathrm{O}, \mathrm{S}, \mathrm{Se}, \mathrm{Te})$ doped $\mathrm{CoSb}_{3}$ and $\Delta N^{i}$ is the change in the composition due to the presence of the point defect at a given temperature $T$, which can be calculated by summing over the carriers $c_{j}$ of each defect $j$, weighted by the change in composition $N_{j}^{i}$ due to the defect,

$$
\Delta N^{i}=\sum_{j} N_{j}^{i} c_{j}
$$

Using Eqn (9) and (10), we predicted the solubility limits of dopant $M(M=\mathrm{O}, \mathrm{S}, \mathrm{Se}, \mathrm{Te})$ as functions of temperature in $\mathrm{CoSb}_{3}$ system, as shown in Figure 6. Because the carrier concentration in Co rich condition is much higher compared with that in $\mathrm{Sb}$ rich condition (Figure 5), the solubility limit $x$ of dopant $M$ in the Co rich condition is much larger over the entire temperature range. Above the eutectic temperature $(900 \mathrm{~K})$ in $\mathrm{CoSb}_{3}-\mathrm{Sb}$, the solvus boundaries are in metastable equilibrium, which we plot with dashed lines in Figure 6. The solubility limit of Te is higher than Se, and much higher than S. The predicted solubility limit of Te shows agreement with the experimental data, ${ }^{20,26}$ as embedded in Figure 6(d). S has a tiny solubility in pure $\mathrm{CoSb}_{3}$ system, but it can be further soluble within $\mathrm{CoSb}_{3-\mathrm{y}} \mathrm{Te}_{\mathrm{y}}$ system in the Co rich region due to the lower formation energy of $\mathrm{S}_{\mathrm{i}}+\mathrm{Te}_{\mathrm{Sb}}$ than $\mathrm{S}_{\mathrm{Sb}}$ as plotted in Figure 2(c) and 2(d). This is consistent with the experimental observations. ${ }^{42}$ 

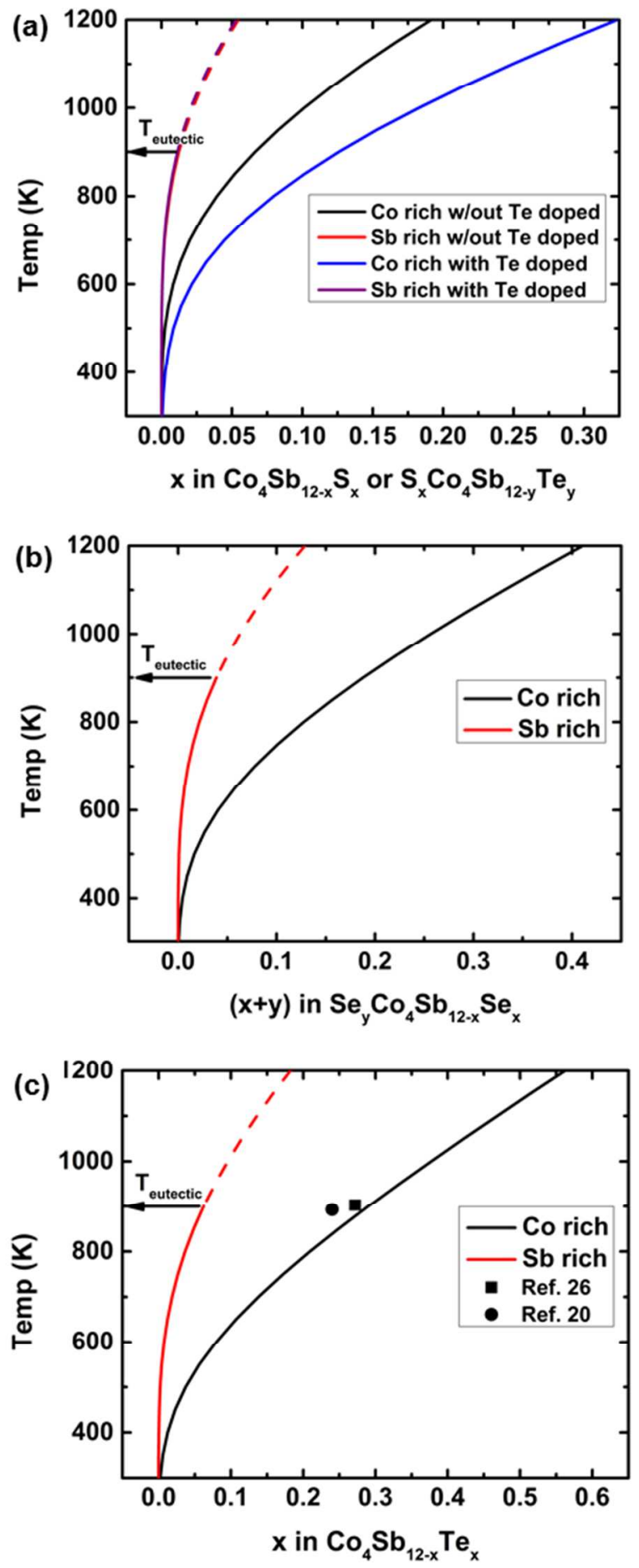

Figure 6. Predicted solubility limits of (a) $\mathrm{S}$ in $\mathrm{Co}_{4} \mathrm{Sb}_{12}$ and $\mathrm{Co}_{4} \mathrm{Sb}_{12-\mathrm{y}} \mathrm{Te}_{\mathrm{y}}$, (b) $\mathrm{Se}$ in $\mathrm{Co}_{4} \mathrm{Sb}_{12}$, and (c) $\mathrm{Te}$ in $\mathrm{Co}_{4} \mathrm{Sb}_{12}$. Experimental solubility limit of $\mathrm{Te}$ in $\mathrm{Co}_{4} \mathrm{Sb}_{12}$ are embedded for comparison. The nominal experimental solubility limit of Te substituting $\mathrm{Sb}$ is found to be $x=0.55-0.6$ in $\mathrm{Co}_{4} \mathrm{Sb}_{12-x} \mathrm{Te}_{x}$. ${ }^{18,20,24-26}$ 
However, the actual solubility limit was found to be $x=0.272$ and 0.24 by EPMA measurements in Refs. 20 and 26, respectively. Thus, we only compared our predicted solubility limit with the actual solubility limit presented in Refs. 20 and 26.

\subsection{Possible role of point defects on transport properties in doped $\mathrm{CoSb}_{3}$}

Present theories and experiments focus on studying the interaction between the guest and host atoms as well as its influence on TE properties of $\mathrm{CoSb}_{3} \cdot{ }^{15-17,43}$ However, the breakage of $\mathrm{Sb}_{4}$-rings induced by doping atoms is surprisingly overlooked so far. For single-atom-doped $\mathrm{CoSb}_{3}$, the new interstitial site $\left(M_{\mathrm{i}-7}\right)$ induces breakage of $\mathrm{Sb}_{4}$-rings such as $\mathrm{O}_{\mathrm{i}}$ as shown in Figure 3(a) and provides a new prospective for understanding the role of doping atoms in $\mathrm{CoSb}_{3}$ along with its effects on transport properties. Double-atom-doped $\mathrm{CoSb}_{3}, \mathrm{~S}_{\mathrm{Sb}}+\mathrm{Te} \mathrm{Sb}_{\mathrm{Sb}}$ and $\mathrm{S}_{\mathrm{i}}+\mathrm{Te}_{\mathrm{Sb}}$ structures shown in Figure 3(c) and 3(d), are beneficial for further understanding the complicated chemical structure of other dopants in $\mathrm{CoSb}_{3}$, especially for the controversial group 13 dopants (Ga and In). ${ }^{10,15,16,43}$ The novel $\mathrm{S}_{\mathrm{i}}+\mathrm{Te}_{\mathrm{Sb}}$ structure shown in Figure 3(c) leads to the formation of a lone pair of Te $p$ orbitals. This should remarkably reduce the thermal conductivity of $\mathrm{CoSb}_{3}$ as similarly reported for e.g., bournonites and tetrahedrites, ${ }^{44-47}$ hence resulting in a high $z T$ value of doped $\mathrm{CoSb}_{3}$. For example, in $\mathrm{Co}_{4} \mathrm{Sb}_{12-y} \mathrm{Te}_{y}$ system, $\mathrm{Te}_{\mathrm{Sb}}$ is an effective approach to reduce the lattice thermal conductivity $\left(\kappa_{\mathrm{L}}\right)$ from $\sim 10 \mathrm{Wm}^{-1} \mathrm{~K}^{-1}$ to $\sim 3 \mathrm{Wm}^{-1} \mathrm{~K}^{-1}$ at room temperature because of point defect and electron-phonon scattering. ${ }^{18,20,24-26} \mathrm{~S}$ filler atoms within $\mathrm{Co}_{4} \mathrm{Sb}_{12-y} \mathrm{Te}_{y}$ further lowers the $\kappa_{\mathrm{L}}$ to $\sim 1.5 \mathrm{Wm}^{-1} \mathrm{~K}^{-1}$ for $\mathrm{S}_{0.26} \mathrm{Co}_{4} \mathrm{Sb}_{11.11} \mathrm{Te}_{0.73}$ at room temperature. ${ }^{17}$ Moreover, $\mathrm{S}$ filler atoms decrease the electrical conductivity $(\sigma)$ within n-type Te doped $\mathrm{CoSb}_{3},{ }^{17}$ contributing to the p-type conduction behavior of $\mathrm{S}_{\mathrm{i}}+\mathrm{Te}_{\mathrm{Sb}}$ observed in Figure 2(c). Meanwhile, due to the typical degenerate semiconducting behavior, S filler atoms increase the Seebeck coefficient $(\alpha)$ within Te doped $\mathrm{CoSb}_{3} .{ }^{17} \mathrm{In}$ addition to $\mathrm{S}+\mathrm{Te}$ dopants, many other dopants such as $\mathrm{Cl}_{\mathrm{i}}+\mathrm{Te}_{\mathrm{Sb}}$ and $\mathrm{Br}_{\mathrm{i}}+\mathrm{Te}_{\mathrm{Sb}}$, etc., might lead to a similar structure shown in Figure 3(c) and can potentially improve the TE properties of $\mathrm{CoSb}_{3}$ further. We believe this work provides a new defect-engineering strategy to determine the electronic structure and phase stability in doped $\mathrm{CoSb}_{3}$, which could be applied to other TE and non-TE energy materials with open structures.

\section{CONCLUSIONS}

We applied density functional theory based defect energy calculations to investigate the point defect chemistry of impurity dopants $M(M=\mathrm{O}, \mathrm{S}, \mathrm{Se}, \mathrm{Te})$ in $\mathrm{CoSb}_{3}$. We found that the 
neutral $\mathrm{O}_{\mathrm{i}}$ is the dominant point defect, which can be explained by the breakage of the $\mathrm{Sb}_{4}$-ring and the formation of an interesting $\mathrm{O}-4 \mathrm{Sb}$ five-membered ring. $M_{\mathrm{Sb}}(M=\mathrm{S}, \mathrm{Se}, \mathrm{Te})$ is more stable than $M_{\mathrm{i}}$, indicating $M_{\mathrm{Sb}}$ is the dominant n-type single point defect in $\mathrm{CoSb}_{3}$. However, $\mathrm{Se}_{\mathrm{i}}$ can exist in $\mathrm{Se}$ doped $\mathrm{CoSb}_{3}$ by the formation of the complex defect $\mathrm{Se}_{\mathrm{i}}+\mathrm{Se}_{\mathrm{sb}}$. Due to the positive binding energy of the complex defect $\mathrm{S}_{\mathrm{i}}+\mathrm{Te}_{\mathrm{Sb}}, \mathrm{S}_{\mathrm{i}}$ can stably form and collapse the Te-3Sb fourmembered ring within Te doped $\mathrm{CoSb}_{3}$, leading to $\mathrm{p}$-type conduction behavior and the formation of lone pairs of Te $p$ orbitals. Because $\mathrm{Se}_{\mathrm{Sb}}+\mathrm{Te}_{\mathrm{Sb}}$ has a lower formation energy compared to $\mathrm{Se}_{\mathrm{i}}+\mathrm{Te}_{\mathrm{Sb}}$ in the Co rich region, $\mathrm{Se}_{\mathrm{Sb}}$ is easier to form than $\mathrm{Se}_{\mathrm{i}}$ within Te doped $\mathrm{CoSb}_{3}$. $\mathrm{Se}_{\mathrm{Sb}}$ breaks the Se-Te-2Sb four-membered ring within Te doped $\mathrm{CoSb}_{3}$, resulting in a neutral behavior. The solubility limit of Te is higher than Se, and much higher than S. S has a tiny solubility in pure $\mathrm{CoSb}_{3}$ system, but it can be further soluble within $\mathrm{CoSb}_{3-\mathrm{y}} \mathrm{Te}_{\mathrm{y}}$ system in the Co rich region due to the lower formation energy of $\mathrm{S}_{\mathrm{i}}+\mathrm{Te}_{\mathrm{Sb}}$ than $\mathrm{S}_{\mathrm{Sb}}$.

\section{ACKNOWLEDGEMENTS}

This work is partially supported by National Basic Research Program of China (973program) under Project No. 2013CB632505, the 111 Project of China under Project No. B07040, Materials Project by Department of Energy Basic Energy Sciences Program under Grant No. EDCBEE, DOE Contract DE-AC02-05CH11231, and China Postdoctoral Science Foundation (408-32200031). We would like to acknowledge the Jet Propulsion Laboratory, California Institute of Technology, as a funding source under a contract with the National Aeronautics and Space Administration, which was supported by the NASA Science Missions Directorate's Radioisotope Power Systems Technology Advancement Program.

Supporting information: The additional remarks in our calculation, initial single point defect structures for the three types of defects in $M(M=\mathrm{O}, \mathrm{S}, \mathrm{Se}, \mathrm{Te})$ doped $\mathrm{Co}_{8} \mathrm{Sb}_{24}$, and initial local atomic structure of neutral $\mathrm{S}_{\mathrm{Sb}}+\mathrm{Te}_{\mathrm{Sb}}$ complex defect in $\mathrm{S}$ and Te co-doped $\mathrm{Co}_{64} \mathrm{Sb}_{192}$.

\section{REFERENCES}

(1) Yang, J.; Caillat, T. Thermoelectric Materials for Space and Automotive Power Generation. MRS Bull. 2006, 31, 224-229.

(2) Snyder, G. J.; Toberer, E. S. Complex Thermoelectric Materials. Nat. Mater. 2008, 7, 105-114.

(3) Takabatake, T.; Suekuni, K.; Nakayama, T., Phonon-Glass Electron-Crystal Thermoelectric Clathrates: Experiments and Theory. Rev. Mod. Phys. 2014, 86, 669-716. 
(4) Aydemir, U.; Candolfi, C.; Ormeci, A.; Baitinger, M.; Burkhardt, U.; Oeschler, N.; Steglich, F.; Grin, Y., Electronic Band Structure and Low-Temperature Transport Properties of the Type-I Clathrate $\mathrm{Ba}_{8} \mathrm{Ni}_{\mathrm{x}} \mathrm{Ge}_{46-\mathrm{x}-\mathrm{y} .}$. Dalton. Trans. 2015, 44, 7524-7537.

(5) Slack, G. A.; In CRC Handbook of Thermoelectrics: New Materials and Performance Limits for Thermoelectric Cooling; Rowe, D. M., Eds.; CRC Press, 1995; Chapter 34.

(6) Uher, C.; In Handbook of Thermoelectrics: Macro to Nano; Rowe, D. M., Eds.; CRC Press: Boca Raton, FL, 2006; Chapter 34, pp 1-17.

(7) Nolas, G. S.; Morelli, D. T.; Tritt, T. M., Skutterudites: A Phonon-Glass-Electron Crystal Approach to Advanced Thermoelectric Energy Conversion Applications. Annu. Rev. Mater. Sci. 1999, 29, 89-116.

(8) Li, G. D.; An, Q.; Li, W. J.; Goddard, W. A.; Zhai, P. C.; Zhang, Q. J.; Snyder, G. J., Brittle Failure Mechanism in Thermoelectric Skutterudite $\mathrm{CoSb}_{3}$. Chem. Mater. 2015, 27, 6329-6336.

(9) Li, G. D.; An, Q.; Goddard, W. A.; Hanus, R.; Zhai, P. C.; Zhang, Q. J.; Snyder, G. J., Atomistic Explanation of Brittle Failure of Thermoelectric Skutterudite $\mathrm{CoSb}_{3}$. Acta. Mater. 2016, 103, 775-780.

(10) Tang, Y. L.; Qiu, Y. T.; Xi, L. L.; Shi, X.; Zhang, W. Q.; Chen, L. D.; Tseng, S. M.; Chen, S. W.; Snyder, G. J. Phase Diagram of In-Co-Sb System and Thermoelectric Properties of In-Containing Skutterudites. Energy Environ. Sci. 2014, 7, 812-819.

(11) Mi, J. L.; Zhao, X. B.; Zhu, T. J.; Tu, J. P.; Nanosized La Filled $\mathrm{CoSb}_{3}$ Prepared by a SolothermalAnnealing Method. Matt. Lett. 2008, 62, 2363-2365.

(12) Tang, Y. L.; Hanus, R.; Chen, S. W.; Snyder, G. J., Solubility Design Leading to High Figure of Merit in Low-Cost Ce-CoSb 3 Skutterudites. Nat. commun. 2015, 6, 7584.

(13) Rogl, G.; Grytsiv, A.; Rogl, P.; Peranio, N.; Bauer, E.; Zehetbauer, M.; Eibl, O., n-Type Skutterudites $(\mathrm{R}, \mathrm{Ba}, \mathrm{Yb})_{\mathrm{y}} \mathrm{Co}_{4} \mathrm{Sb}_{12}(\mathrm{R}=\mathrm{Sr}, \mathrm{La}, \mathrm{Mm}, \mathrm{DD}, \mathrm{SrMm}, \mathrm{SrDD})$ Approaching $\mathrm{ZT} \approx 2.0$. Acta. Mater. 2014, 63, $30-43$.

(14) Qiu, Y.; Xi, L.; Shi, X.; Qiu, P.; Zhang, W.; Chen, L.; Salvador, J. R.; Cho, J. Y.; Yang, J.; Chien, Y.c.; Chen, S.-w.; Tang, Y.; Snyder, G. J., Charge-Compensated Compound Defects in Ga-containing Thermoelectric Skutterudites. Adv. Func. Mater. 2013, 23, 3194-3203.

(15) Xi, L.; Qiu, Y.; Zheng, S.; Shi, X.; Yang, J.; Chen, L.; Singh, D. J.; Yang, J.; Zhang, W., Complex Doping of Group 13 Elements In and Ga in Caged Skutterudite $\mathrm{CoSb}_{3}$. Acta. Mater. 2015, 85, $112-$ 121.

(16) Shi, X.; Zhang, W.; Chen, L. D.; Yang, J. Filling Fraction Limit for Intrinsic Voids in Crystals: Doping in Skutterudites. Phys. Rev. Lett. 2005, 95, 185503-185503-4.

(17) Duan, B.; Yang, J.; Salvador, J. R.; He, Y.; Zhao, B.; Wang, S.; Wei, P.; Ohuchi, F. S.; Zhang, W.; Hermann, R. P.; Gourdon, O.; Mao, S. X.; Cheng, Y.; Wang, C.; Liu, J.; Zhai, P.; Tang, X.; Zhang, Q.; Yang, J., Electronegative Guests in $\mathrm{CoSb}_{3}$. Energy Environ. Sci. 2016, 9, 2090-2098.

(18) Zhang, Q.; Li, X.; Kang, Y.; Zhang, L.; Yu, D.; He, J.; Liu, Z.; Tian, Y.; Xu, B., High Pressure Synthesis of Te-doped $\mathrm{CoSb}_{3}$ with Enhanced Thermoelectric Performance. J. Mater. Sci: Mater. Electron. 2014, 26, 385-391. 
(19) Liang, T.; Su, X.; Yan, Y.; Zheng, G.; Zhang, Q.; Chi, H.; Tang, X.; Uher, C., Ultra-Fast Synthesis and Thermoelectric Properties of Te Doped Skutterudites. J. Mater. Chem. A. 2014, 2, 17914-17918.

(20) Duan, B.; Zhai, P.; Liu, L.; Zhang, Q.; Ruan, X., Synthesis and High Temperature Transport Properties of Te-doped Skutterudite Compounds. J. Mater. Sci: Mater. Electron. 2012, 23, 1817-1822.

(21) Liu, W. S.; Zhang, B. P.; Zhao, L. D.; Li, J. F., Improvement of Thermoelectric Performance of $\mathrm{CoSb}_{3-\mathrm{x}} \mathrm{Te}_{\mathrm{x}}$ Skutterudite Compounds by Additional Substitution of IVB-Group Elements for Sb. Chem. Mater. 2008, 20, 7526-7531.

(22) Ur, S. C.; Kwon, J. C.; Kim, I. H., Thermoelectric Properties of Fe-doped $\mathrm{CoSb}_{3}$ Prepared by Mechanical Alloying and Vacuum Hot Pressing. J. Alloys. Compds. 2007, 442, 258-361.

(23) Kitagawa, H.; Wakatsuki, M.; Nagaoka, H.; Noguchi, H.; Isoda, Y.; Hasezaki, K.; Noda, Y., Temperature Dependence of Thermoelectric Properties of Ni-doped $\mathrm{CoSb}_{3}$. J. Phys. Chem. Solids. 2005, 66, 1635-1639.

(24) Li, X. Y.; Chen, L. D.; Fan, J. F.; Zhang, W. B.; Kawahara, T.; Hirai, T., Thermoelectric Properties of Te-doped $\mathrm{CoSb}_{3}$ by Spark Plasma Sintering. J. Appl. Phys. 2005, 98, 083702-1 - 083702-6.

(25) Liu, W.-S.; Zhang, B.-P.; Li, J.-F.; Zhang, H.-L.; Zhao, L.-D., Enhanced Thermoelectric Properties in $\mathrm{CoSb}_{3-\mathrm{x}} \mathrm{Te}_{\mathrm{x}}$ Alloys Prepared by Mechanical Alloying and Spark Plasma Sintering. J. Appl. Phys. 2007, 102, 103717-1 - 103717-7.

(26) Wojciechowski, K. T.; Toboła, J.; Leszczyński, J., Thermoelectric Properties and Electronic Structure of $\mathrm{CoSb}_{3}$ doped with Se and Te. J. Alloys. Compds. 2003, 361, 19-27.

(27) Zhao, D.; Tian, C.; Tang, S.; Liu, Y.; Chen, L., High Temperature Oxidation Behavior of Cobalt Triantimonide Thermoelectric Material. J. Alloys. Compds. 2010, 504, 552-558.

(28) Kresse, G.; Furthmuller, J. Efficiency of ab-initio Total Energy Calculations for Metals and Semiconductors Using a Plane-Wave Basis Set. Comp. Mater. Sci. 1996, 6, 15-50.

(29) Kresse, G.; Furthmuller, J. Efficient Iterative Schemes for ab initio Total-Energy Calculations Using a Plane-Wave Basis Set. Phys. Rev. B. 1996, 54, 11169-11186.

(30) Kresse, G.; Joubert, D. From Ultrasoft Pseudopotentials to the Projector Augmented-Wave Method. Phys. Rev. B. 1999, 59, 1758-1775.

(31) Li, G.; Bajaj, S.; Aydemir, U.; Hao, S.; Xiao, H.; Goddard, W. A.; Zhai, P.; Zhang, Q.; Snyder, G. J., p-Type Co Interstitial Defects in Thermoelectric Skutterudite $\mathrm{CoSb}_{3}$ Due to the Breakage of Sb4Rings. Chem. Mater. 2016, 28, 2172-2179.

(32) Zhang, S. B.; Northrup, J. E., Chemical-Potential Dependence of Defect Formation Energies in GaAs - Application to Ga Self-Diffusion. Phys. Rev. Lett. 1991, 67, 2339-2342.

(33) Lany, S.; Zunger, A., Accurate Prediction of Defect Properties in Density Functional Supercell Calculations. Model. Simul. Mater. Sci. 2009, 17, 084002-1-084002-14.

(34) Makov, G.; Payne, M. C., Periodic Boundary-Conditions in Ab-Initio Calculations. Phys. Rev. B. 1995, 51, 4014-4022. 
(35) Duan, X. M.; Stampfl, C., Vacancies and Interstitials in Indium Nitride: Vacancy Clustering and Molecular Bondlike Formation from First Principles. Phys. Rev. B. 2009, 79, 174202.

(36) Svensson, C., The Crystal Structure of Orthorhombic Antimony Trioxide, $\mathrm{Sb}_{2} \mathrm{O}_{3}$. Acta Cryst. B. 1974, $30,458-461$.

(37) Knowles, C. R., A Redetermination of the Structure of Miargyrite, $\mathrm{AgSbS}_{2}$. Acta. Crystallogr. 1964, $17,847-851$.

(38) Zhao, L. D.; Lo, S. H.; Zhang, Y.; Sun, H.; Tan, G.; Uher, C.; Wolverton, C.; Dravid, V. P.; Kanatzidis, M. G., Ultralow Thermal Conductivity and High Thermoelectric Figure of Merit in SnSe Crystals. Nature. 2014, 508, 373-377.

(39) Tideswell, N. W.; Kruse, F. H.; McCullough, J. D., The Crystal Structure of Antimony Selenide, $\mathrm{Sb}_{2} \mathrm{Se}_{3}$. Acta Crystallogr. 1957, 10, 99-102.

(40) Park, C.-H.; Kim, Y.-S., Ab Initio Study of Native Point-Defects in $\mathrm{CoSb}_{3}$ : Understanding offStoichiometric Doping Properties. Phys. Rev. B. 2010, 81, 085206-1-085206-7.

(41) Bjerg, L.; Madsen, G. K. H.; Iversen, B. B., Ab initio Calculations of Intrinsic Point Defects in ZnSb. Chem. Mater. 2012, 24, 2111-2116.

(42) Duan, B.; Zhai, P. C.; Xu, C. L.; Ding, S. J.; Li, P,; Zhang, Q. J., Thermoelectric Performance of Tellurium and Sulfur Double-Substituted Skutterudite Materials. J. Mater. Sci. 2014, 49, 4445-4452.

(43) Xi, L. L.; Yang, J.; Lu, C. F.; Mei, Z. G.; Zhang, W. Q.; Chen, L. D. Systematic Study of the Multiple-Element Filling in Caged Skutterudite $\mathrm{CoSb}_{3}$. Chem. Mater. 2010, 22, 2384-2394.

(44) Lu, X.; Morelli, D. T., Natural Mineral Tetrahedrite as a Direct Source of Thermoelectric Materials. Phys. Chem. Chem. Phys. 2013, 15, 5762-5766.

(45) Lu, X.; Morelli, D. T.; Xia, Y.; Zhou, F.; Ozolins, V.; Chi, H.; Zhou, X. Y.; Uher, C., High Performance Thermoelectricity in Earth-Abundant Compounds Based on Natural Mineral Tetrahedrites. Adv. Energy. Mater. 2013, 3 (3), 342-348.

(46) Faghaninia, A.; Yu, G.; Aydemir, U.; Wood, M.; Chen, W.; Rignanese, G. M.; Snyder, G. J.; Hautier, G.; Jain, A., A Computational Assessment of the Electronic, Thermoelectric, and Defect Properties of Bournonite $\left(\mathrm{CuPbSbS}_{3}\right)$ and Related Substitutions. Phys. Chem. Chem. Phys. 2017, 19, 6743-6756.

(47) Dong, Y.; Khabibullin, A. R.; Wei, K.; Salvador, J. R.; Nolas, G. S.; Woods, L. M., Bournonite $\mathrm{PbCuSbS}_{3}$ : Stereochemically Active Lone-Pair Electrons that Induce Low Thermal Conductivity. Chemphyschem 2015, 16 (15), 3264-3270. 
The TOC Figure:
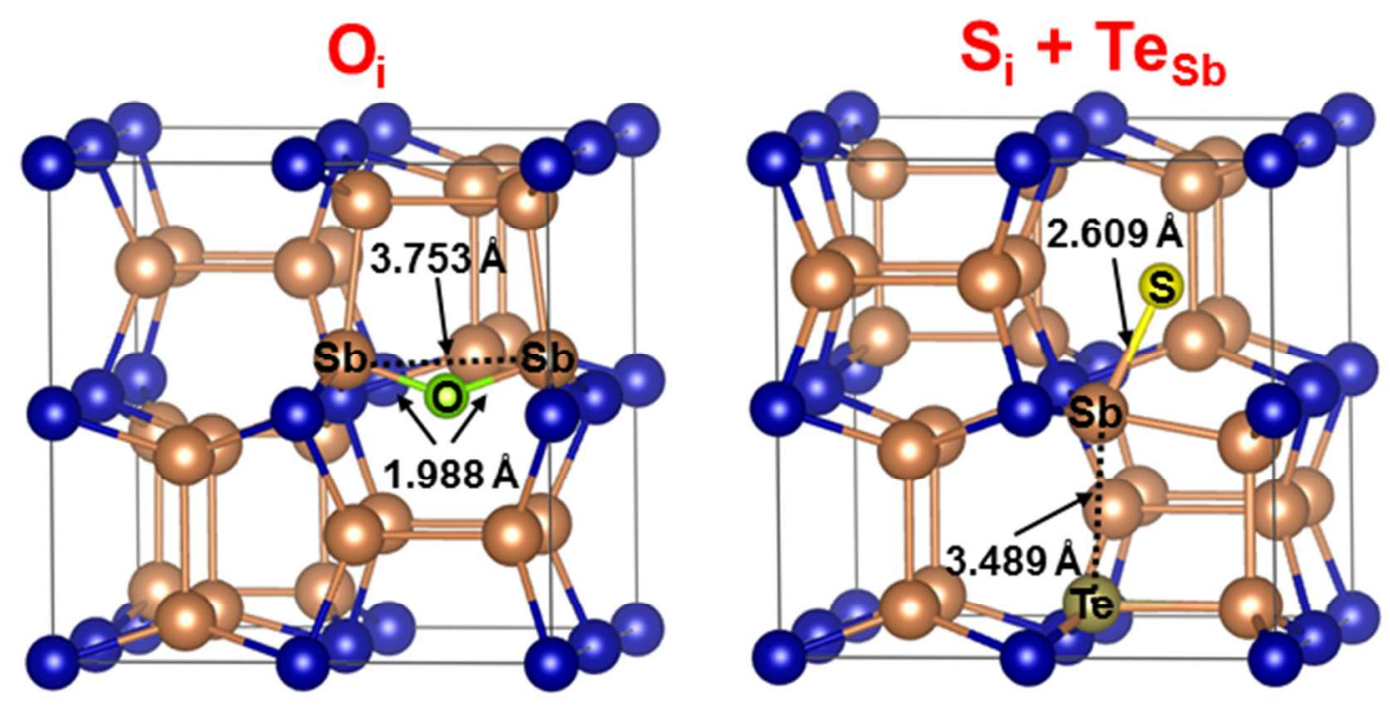

22 